\title{
Chromosome weights and measures in Petunia
}

\author{
Julia White and \\ H. Rees
}

Department of Agricultural Botany, University

College of Wales, Aberystwyth.

The $2 C$ nuclear DNA amounts in diploid Petunia species are low, ranging from 1.73 to $3 \cdot 00$ picograms. The nuclear dry mass and the total chromosome volume are closely correlated with the nuclear DNA amount. So also is cell size measured in pollen grains. Increase in the total nuclear DNA within the genus is achieved by the addition of equal increments of DNA to all members of the chromosome complement irrespective of their size. It is suggested that the correlations and distribution patterns of DNA changes displayed by the natural species may serve as standards for monitoring and interpreting changes in genetic material which are associated with regeneration from protoplasts and callus.

\section{INTRODUCTION}

Many species of the family Solanacae are notable for their tolerance of the manipulations of scientists engaged in regenerating plants from pollen grains, callus tissue and protoplasts and, at the molecular level, in genetic transformation by "foreign" genes. In the genus Petunia regeneration of plants following protoplast fusion has been employed with particular success to create novel interspecific "somatic" hybrids (Cocking et al., 1977; Power et al., 1979). It is partly for this reason that we present, below, an account of the nuclear properties of Petunia species. The information should be useful in the context of monitoring and interpreting the changes in genetic material which commonly arise during or following the regeneration of somatic hybrids (e.g., White and Rees, 1985). The nuclear properties described are genome size (the nuclear DNA amount) and the nuclear dry mass; the number, size, DNA content of the chromosomes; their relationship to one another and with cell size. The information contributes, as well, to our general store of knowledge about the evolution of the nuclear phenotype of Angiosperms, in particular about the distribution pattern of DNA changes among individual chromosomes within complements.

\section{MATERIAL AND METHODS}

Seeds of six species investigated were obtained from Professor Cocking of Nottingham University to whom we are grateful.

Chromosome volumes were estimated from measurements at metaphase of mitosis in meristems of roots after immersion for 18 hours in distilled water in an ice box, fixation in acetic alcohol, hydrolysis in $1 \mathrm{~N} \mathrm{HCl}$ for 10 minutes and staining in Feulgen solution. The volumes were calculated on the assumption that each chromatid is a solid cylinder. Volumes for each species are based on the mean of three metaphases, one in each of three different plants.

For nuclear DNA measurements root tips were fixed in 4 per cent formaldehyde in neutral buffer for 2 hours, washed in distilled water for 24 hours, fixed again in acetic alcohol for 24 hours, washed in distilled water for 30 minutes, hydrolysed in $5 \mathrm{~N}$ $\mathrm{HCl}$ at room temperature and stained in Feulgen solution at $p \mathrm{H} 2 \cdot 2$ for 1 hour. After further washing in $\mathrm{SO}_{2}$ water the root meristems were squashed in 45 per cent acetic acid. $2 C$ anaphase nuclei were scanned at a wavelength of $565 \mathrm{~nm}$. using a Vickers M86 microdensitometer. Allium cepa roots were used as controls and for converting the microdensitometer readings to picograms, using $33 \cdot 5$ 
picograms as the Allium cepa standard. Data from 10 nuclei in each of 3 replicates (plants) in each species.

For measurements of dry mass nuclei from root tips were isolated according to the method of McLeish (1963) with modifications described by Evans (1968). The dry mass was estimated using the Vickers M86 scanning-interferometer. The theory of interference and its application to dry mass measurements is given by Barer (1956) and Davies (1958). Data are from 3 replicates of 10 nuclei in each species.

Pollen cell size was estimated after fixing ripe pollen grains in acetic alcohol and staining in aceto-carmine. Diameters were estimated from measurements using an Olympus micrometer eye piece. Means are based on at least 3 replicates of 20 cells each.

\section{RESULTS}

\section{Measurements and correlations}

Table 1 shows the $2 C$ DNA amounts to be low for all species but, at the same time, a considerable variation between them. Petunia parviflora which has the highest chromosome number $(2 n=18)$ has least DNA, about 70 per cent less than $P$. parodii, one of the five species with $2 n=14$.

Table 1 Chromosome numbers, nuclear DNA amount in pgs., nuclear dry mass in pgs., the total chromosome volume at metaphase in microns cubed and the diameter of pollen grains in microns in Petunia species

\begin{tabular}{|c|c|c|c|c|c|}
\hline Species & $n$ & $\begin{array}{l}2 C \\
\text { DNA } \\
\text { amount }\end{array}$ & $\begin{array}{l}2 C \\
\text { nuclear } \\
\text { dry mass }\end{array}$ & $\begin{array}{l}\text { Total } \\
\text { Chromo- } \\
\text { some } \\
\text { volume }\end{array}$ & $\begin{array}{l}\text { Pollen } \\
\text { grain } \\
\text { diameter }\end{array}$ \\
\hline P. parodii & 7 & $3 \cdot 00$ & $23 \cdot 8$ & 8.97 & $40 \cdot 51$ \\
\hline P. axillaris & 7 & $2 \cdot 81$ & $26 \cdot 6$ & $8 \cdot 61$ & $39 \cdot 92$ \\
\hline P. hybrida & 7 & $2 \cdot 73$ & $21 \cdot 9$ & $8 \cdot 11$ & $36 \cdot 18$ \\
\hline P. violacaea & 7 & $2 \cdot 55$ & $20 \cdot 4$ & $7 \cdot 02$ & $31 \cdot 71$ \\
\hline P. inflata & 7 & $2 \cdot 41$ & $19 \cdot 7$ & $6 \cdot 60$ & 31.99 \\
\hline P. parviflora & 9 & 1.73 & $15 \cdot 8$ & 4.80 & $28 \cdot 41$ \\
\hline
\end{tabular}

Table 1 and fig. 1(a) show that the DNA amount and the nuclear dry mass are correlated $(P=<0 \cdot 01)$. That the relationship between them is linear is evidence that the DNA accounts for a consistent fraction of the total mass in $2 \mathrm{C}$ nuclei. On average it is approximately 12 per cent.

When the total chromosome volumes from Table 1 are plotted against the DNA amounts (fig. 1(b)) there is again a significant, linear regression $(P)=<0 \cdot 01)$. The linearity testifies to a similar density of DNA per unit volume of the metaphase chromosomes from all five species.

In fig. 1(c) the diameters of pollen grains are plotted against nuclear DNA amounts. The regression is significant at the 1 per cent level.

\section{DNA variation within complements}

As described the chromosome volume is very closely correlated with DNA amount. Given the volumes of individual chromosomes one may readily estimate, therefore, their DNA contents. These are presented in table 2 for each chromosome of the haploid complement of each species. This information allows us to determine how change in the total nuclear DNA is distributed among individual chromosomes within the complement.

In fig. 2 the DNA amount for each chromosome in rank order, from small to large in each species, is plotted against the mean DNA amount of each of the seven chromosomes, also in rank order, of the five species with $n=7$. The figure shows five roughly parallel regression lines with, of course, a positive slope. The regression analysis of variance in table 3 confirms a significant joint regression and also, as expected, a significant difference between the mean DNA amounts in the different species. Of chief interest is that there is no significant heterogeneity between the regression lines $(P=>0 \cdot 20)$, confirming their parallel alignment. It is this homogeneity that tells us how the "extra" DNA is distributed within complements with increase in the total DNA. It tells us that each chromosome gains exactly the same increment of DNA irrespective of its size. This is to say that with the addition of every picogram to the total nuclear DNA each chromosome, small and large alike, acquires an increment of $c a$. one seventh of a picogram. If, as alternatives, the large chromosomes had acquired more DNA than the smaller chromosomes the regression lines in fig. 2 would diverge from left to right; if they had acquired less the lines would converge.

The conclusion that the DNA increment is the same for all chromosomes does of course rest on the assumption that the rank order in chromosome size and DNA content corresponds to the order of homology. The assumption is, in the first place, reasonable and, in the second, well supported in a number of genera by corroborative evidence (Seal and Rees, 1982).

Precisely the same pattern of distribution of DNA change within complements has been described in Lolium and Festuca (Seal and Rees, 

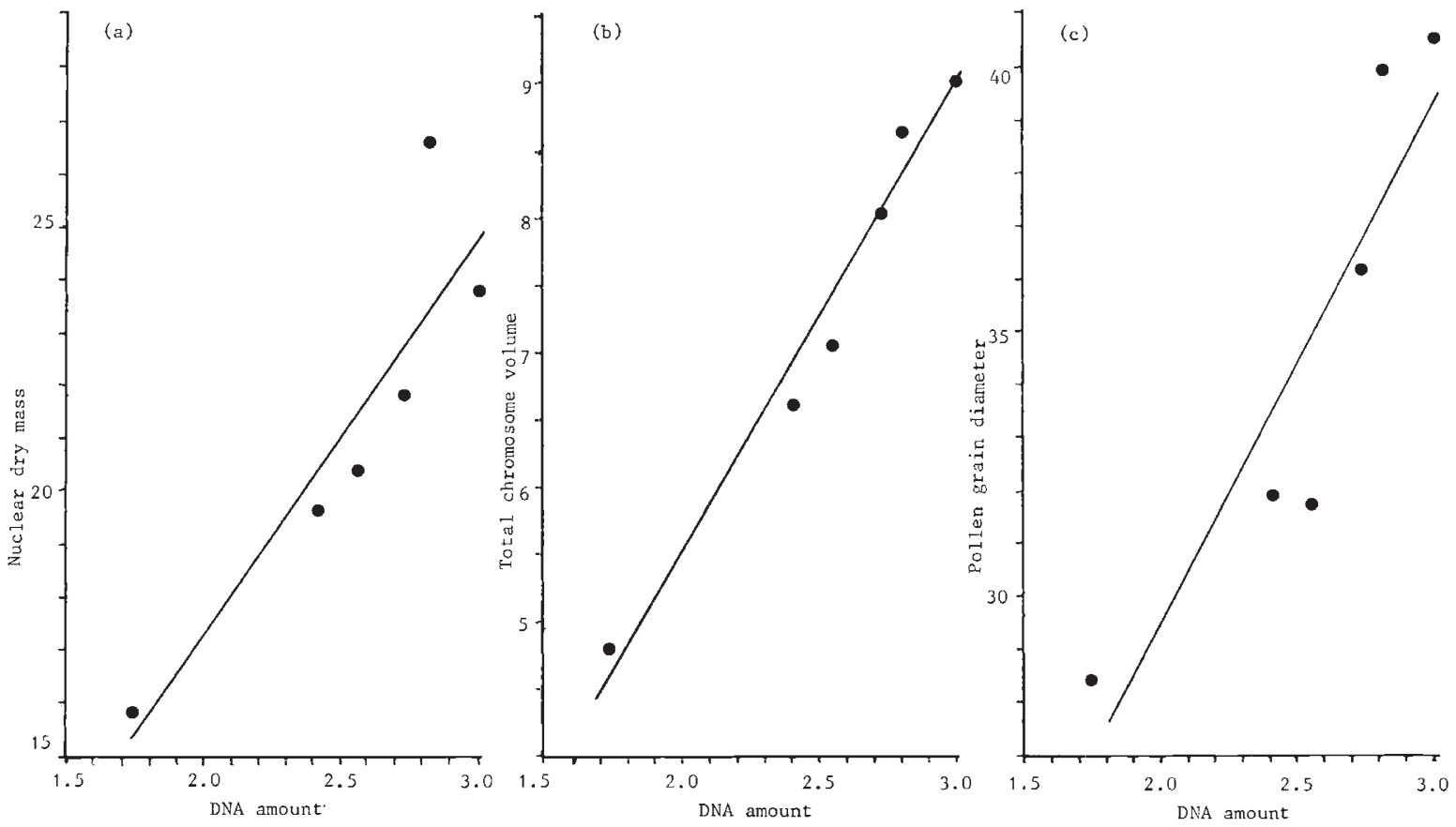

Figure 1 (a) The $2 C$ nuclear dry mass plotted against the $2 C$ nuclear DNA amounts. Values in picograms. (b) The total chromosome volumes at metaphase (microns ${ }^{3}$ ) plotted aginst the $2 C$ DNA amounts. (c) The mean diameters of pollen grains (microns) plotted against the DNA amounts.

loc. cit.), in Lathyrus (Narayan, 1982), Vicia (Raina and Rees, 1983) and Allium (Rees, 1984). It implies that the base sequence amplification within the DNA molecule of each chromosome is independent of its length. It follows, as a corollary, that the amplification is not at random within the nuclear DNA as a whole but rigidly constrained. Some consequences of such constraint have been discussed elsewhere (Rees, loc. cit.).

We have omitted $P$. parviflora from the analysis for the obvious reason that its evolution was accompanied by numerical chromosome change of an unspecified origin.

\section{DISCUSSION}

Correlations of the kind described in Petunia, between nuclear DNA amount, the nuclear dry mass, the chromosome volume and cell size have been reported in a wide range of plant and animal genera (see Cavalier-Smith, 1978). As indicated above there are also reports of constraints, similar to those in Petunia, upon the distribution of DNA change within complements. In all these respects the information presented, albeit an useful supplement to knowledge in this general field, contains nothing that is novel in principle or which, in itself,

Table 2 The DNA amount per chromosome at metaphase of mitosis of the haploid complements in rank order of increasing size and DNA content

\begin{tabular}{|c|c|c|c|c|c|c|c|c|c|}
\hline \multirow[b]{2}{*}{ Species } & \multicolumn{9}{|c|}{ DNA amount per chromosome } \\
\hline & 1 & 2 & 3 & 4 & 5 & 6 & 7 & 8 & 9 \\
\hline$P$. parodii & 0.38 & 0.39 & 0.39 & 0.43 & 0.43 & 0.47 & 0.51 & & \\
\hline P. axillaris & 0.33 & 0.34 & $0 \cdot 37$ & $0 \cdot 39$ & 0.41 & 0.48 & 0.49 & & \\
\hline P. hybrida & $0 \cdot 29$ & 0.35 & $0 \cdot 38$ & 0.41 & 0.41 & 0.43 & 0.47 & & \\
\hline P. violacaea & 0.28 & 0.33 & 0.34 & 0.37 & 0.38 & 0.39 & 0.46 & & \\
\hline P. inflata & $0 \cdot 29$ & 0.29 & 0.33 & $0 \cdot 34$ & $0 \cdot 34$ & $0 \cdot 40$ & 0.43 & & \\
\hline P. parviflora & $0 \cdot 16$ & $0 \cdot 17$ & 0.18 & 0.18 & $0 \cdot 19$ & $0 \cdot 19$ & 0.21 & 0.22 & $0 \cdot 24$ \\
\hline
\end{tabular}




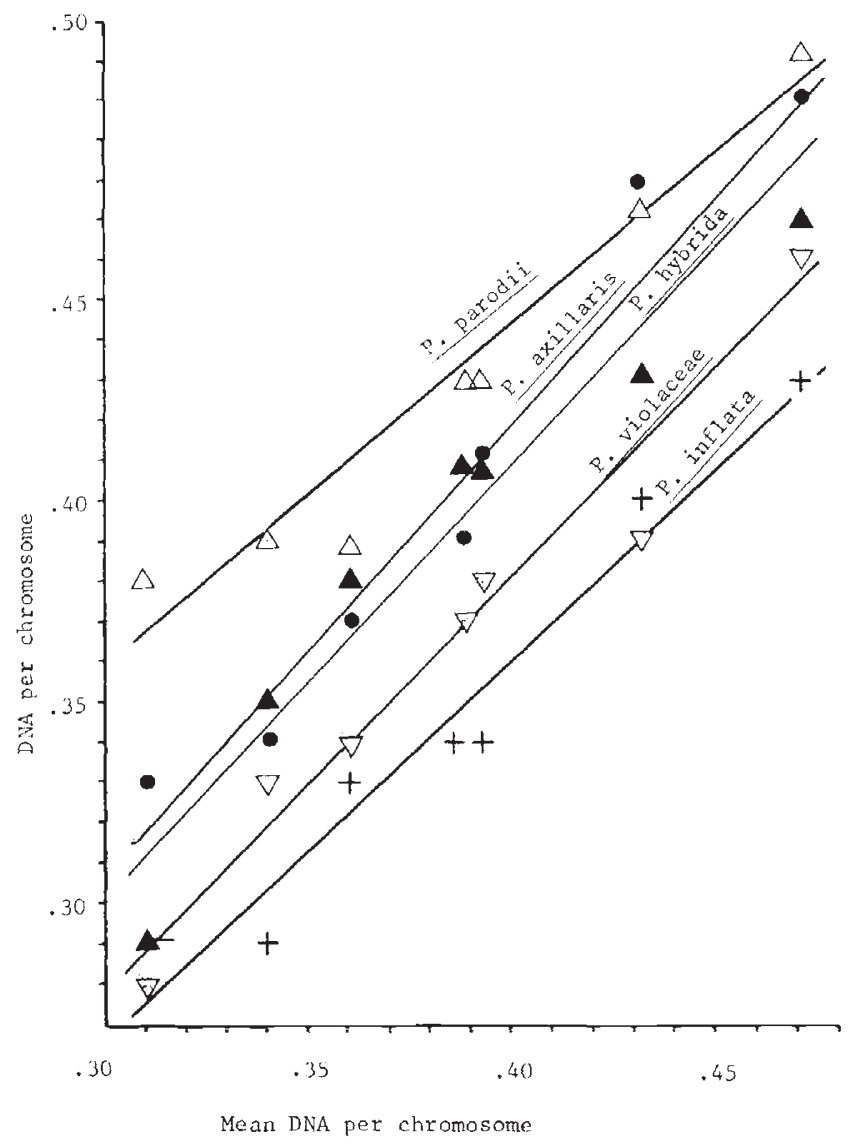

Figure 2 The DNA amount in picograms per metaphase chromosome in rank order of size plotted against the mean DNA amount for each chromosome, also in rank order, for the five species with $n=7$.

Table 3 The joint regression analysis of variance of the DNA amount per chromosome in rank order of size against the mean DNA amount per chromosome, also in rank order, for all five species with $n=7$

\begin{tabular}{llrrrrr}
\hline & SS & $N$ & MS & \multicolumn{1}{c}{$V R$} & $P$ \\
\hline Joint regression & 0.0885 & 1 & 0.0885 & 442.50 & $<0.001$ \\
Het. of regressions & 0.0005 & 4 & 0.0001 & 0.50 & N.S. \\
Het. of means & 0.0292 & 4 & 0.0073 & 36.50 & $<0.001$ \\
Error & 0.0048 & 25 & 0.0002 & & \\
Total & 0.1230 & & & & \\
\hline
\end{tabular}

helps to resolve the many contentious and longstanding arguments which bear, in particular, upon the so-called $c$-value paradox. We suggest that the information might, however, be deployed with benefit in this context.

One of the controversies yet to be resolved is whether the nuclear DNA changes, per se, are the direct causes of the correlated changes in cell size and other aspects of the cell and nuclear phenotype or, alternatively, whether the correlations are consequences of selection for mutually adaptive alterations in these different characters (CavalierSmith, 1978). In Petunia, and other genera, where novel "species" are synthesised following regeneration of the products of protoplast fusion results of the kind presented might be put to good purpose to ask questions which bear upon this particular controversy. In the first place the novel species produced by somatic hybridisation have never been exposed to selection. Second, the manipulations by which the somatic hybrids are synthesised, are themselves the causes of change in genetic material. One might ask therefore whether the correlations which are characteristic of natural species still apply in the somatic hybrids. In short, are they subject to amendment? If not, the selection argument loses strength, and vice versa. Finally, one might ask whether the constraints which are imposed in nature upon the distribution of change in genetic material within the complements apply 
to change consequent upon the manipulations by which the synthetic species are produced. It could be that such constraints reflect a selective intolerance to other than a limited spectrum of options.

\section{REFERENCES}

BARER, R. 1956. The interference microscope in quantitative cytology. Suppl. to 2 nd edition of The Baker Interference Microscope.

CAVALIER-SMITH, T. 1978. Nuclear volume by nucleoskeletal DNA, selection for cell volume and cell growth rate and the solution of the C-DNA paradox. J. Cell Sci., 24, 247278.

COCKING, E. C. 1981. Opportunities from the use of protoplasts. The manipulation of genetic systems in plant breeding. Phil. Trans. R. Soc. Lond. B 292, 401-405.

DAVIES, H. G. 1958. The determination of mass and concentration by microscope interferometry. General Cytochemical Methods, 1. Academic Press.
EVANS, G. M. 1968. Nuclear changes in flax. Heredity, 23, 25-38. MCLEISH, J. 1963. Quantitative relationships between deoxyribonucleic acid and ribonucleic acid in isolated plant nuclei. Proc. Roy. Soc. B 158, 261-278.

NARAYAN, R. K. J. 1982. Discontinuous DNA variation in the evolution of plant species. The genus Lathyrus. Evolution, $36,877-891$.

POWER, J. B., BARRY, S. F., CHAPMAN, J. V., COCKING, E. C. AND SINK, K. C. 1979. Somatic hybrids between unilateral cross-incompatible Petunia species. Theor. Appl. Genet., 55, 97-99.

RAINA, S. N. AND REES, H. 1983. DNA variation between and within chromosome complements of Vicia species. Heredity, 50, 335-346.

REES, H. 1984. Nuclear DNA variation and the homology of chromosomes. Plant Biosystematics, pp. Acad. Press, Toronto, 87-96.

SEAL, A. G. AND REES, H. 1982. The distribution of quantitative DNA changes associated with the evolution of diploid Festuceae. Heredity, 49, 179-190.

WHITE, J. A. AND REES, H. 1984. The chromosome cytology of a somatic hybrid petunia. Heredity, 55, 53-59. 